\title{
Osteoporosis in Iran
}

\author{
Sedigheh Mirhashemi ${ }^{*}$, Mohammad Hosein Kalantar Motamedi' ${ }^{1}$, Amir Hossein Mirhashemi², Shaban \\ Mehrvarz $^{1}$, Zahra Danial'
}

${ }^{1}$ Trauma Research Center, Baqiyatallah University of Medical Sciences, Tehran, Iran
${ }^{2}$ Tehran University of Medical Sciences, Tehran, Iran

*Corresponding Author: Sedigheh Mirhashemi, M.D., Trauma Research Center, Baqiyatallah University of Medical Sciences, Tehran, Iran. Tel: +98-021-88053766, Email: sedmir54@yahoo.com

Received March 28, 2017; Accepted February 27, 2017; Online Published May 31, 2017

\section{Dear Editor,}

Osteoporosis is an important public health problem for older adults. In the Iranian population older than 30 years of age, both osteoporosis and osteopenia are common problems. There is a high prevalence of osteoporosis and vitamin D deficiency in Iran. ${ }^{1,2}$ According to reports, it is estimated that $17 \%$ of Iran's general population aged $>30$ years have osteoporosis and 35\% have osteopenia. The prevalence of these 2 conditions is higher in the northern regions of Iran than in the southern regions, possibly because of their different geographical situations. The northern parts of the country are mostly mountainous, while the majority of the south is covered by deserts. Thus, people living in the southern parts of the country may receive more vitamin $\mathrm{D}$ than residents in the northern parts. ${ }^{3}$

It can be mentioned that bone fracture may be the first symptom of this so called silent disease. Actually, every 3 seconds one osteoporotic fracture occurs somewhere in the world. According to a report by the Iranian Multicenter Osteoporosis Study (IMOS), more than two-thirds of women and half of men over the age of 50 have a low bone mineral density. As life expectancy is increasing the number of older people is also rising. As a result, it has been predicted that by the year 2050, more than half of the osteoporotic fractures around the world will occur in Asia. ${ }^{4}$ Some of the main risk factors for osteoporosis are genetics, advancing age, alcohol consumption, lack of exercise, bad nutrition or eating habits, calcium balance disorders, sex, glucocorticoid use, low BMI, and smoking. There are many other unknown factors as well. Currently, about 6 million elderly people live in Iran. ${ }^{5}$

A study recently conducted by Iran's Ministry of Health showed that $47 \%$ of women and $44 \%$ of men over 50 years of age have deficient bone density, and $6.4 \%$ of people aged 20 to 70 years have osteoporosis of the spine. Moreover, one of every 4 Iranian women over the age of 50 has osteoporosis. Globally, this figure is one in every
3 women; 1 in every 5 men over the age of 50 also suffers from osteoporosis. Statistics in Iran indicate that 50\% of people with osteoporosis have hip fractures. The use of baking soda in bread is a main cause of a lack of calcium in Iranian people; 58 million people in Iran suffer from a calcium deficiency. The use of dairy products in Iran is very limited. Encouraging the consumption of milk enriched with vitamin $\mathrm{D}$, exercise for all age groups, and modifications to dietary habits may partially prevent osteoporosis.

\section{Authors' Contributions}

All authors contributed equally to this study.

\section{Conflict of Interest Disclosures}

The authors declare that they have no conflicts of interest.

\section{Ethical Approval}

Not applicable.

\section{Aknowledgments}

The authors express their gratitude to all researchers at the Trauma Research Center, Baqiyatallah University of Medial Sciences for their kind collaboration.

\section{References}

1. Larijani B, Resch H, Bonjour JP, Meybodi HA, Tehrani MM. Osteoporosis in Iran, overview and management. Iran J Public Health. 2007;Suppl:1-3.

2. Pirdehghan A, Vakili M, Dehghan R, Zare F. High prevalence of vitamin D deficiency and adverse pregnancy outcomes in Yazd, a central province of Iran. J Reprod Infertil. 2016;17(1):34.

3. National Institutes of Health. Dietary supplement fact sheet: vitamin D. https://ods.od.nih.gov/factsheets/VitaminDHealthProfessional/. Published 2011.

4. Rahnavard Z, Zolfaghari M, Hossein-Nezad A, Vahid Dastgerdi M. The incidence of osteoporotic Hip fracture: Iranian Multicenter osteoporosis study (IMOS). Res J Biol Sci. 2009;4(2):171-3.

5. Tajvar M, Arab M, Montazeri A. Determinants of health-related quality of life in elderly in Tehran, Iran. BMC Public Health. 2008;8:323. doi:10.1186/1471-2458-8-323. 